\title{
Innovation and Reconstruction of Management Mode in Internet Era
}

\author{
Hongan Chen \\ East China University of Science and Technology \\ Shanghai, China \\ 364618248@qq.com
}

\author{
Yuhan Bai \\ East China University of Science and Technology \\ Shanghai, China \\ baiyuhan1992412@163.com
}

\begin{abstract}
In the Internet era, enterprises are taking the road from resource driven to innovation driven. We draw attention to the problem that the traditional management mode is no longer suitable for enterprises during the critical transformation period. The aim of this paper is to innovate and reconstruct a new management mode for achieving enterprises' sustainable innovation and long-term development combined with the important features of the Internet. Firstly, using the ambidextrous organization theory as a guide, we provide a stepby-step analytic procedure to put forward the definition and framework of all-involved management mode. Then, we introduce a case study of Haier to provide practical reference for enterprises. Finally, we summarize and discuss the whole paper, and look forward to the future research. Different from other management modes, the mode of this paper is based on shared value and advocates relying on the Internet platform to stimulate endogenous forces and giving full play to employee's potential and creativity.
\end{abstract}

Keywords-Internet, innovation, ambidexterity, all-involved management mode

\section{INTRODUCTION}

The Internet era marked by digitalization, informatization and globalization has broken the original social structure, economic structure and relationship structure [1]. Also, it has brought significant changes in some social factors, such as power, rule, connection and dialogue. Innovation has becomes the main theme of the current age. Many enterprises are trying to change from resource driven to innovation driven. However the practice is not very satisfactory. The reason is that they have not yet realized that the traditional management mode was in a difficult position during the process of enterprise transformation. It is embodied in the following two aspects: First, it is unable to match sustained growth of individual value. The popularity of Internet thinking allows individuals to realize that they are not isolated, but in an interweaving social network Everyone can become the center. They are gradually emerging from dependence on the organization and seeking new development with their own abilities. For example, anyone can use their own idle resources or professional skills to join Internet platform such as Airbnb and Uber. The development of Internet technology brings zero distance and barrier free communication, weakens the asymmetry of information, and expands the organizational boundaries. Grassroots spirit and "Diaosi" thinking are becoming more and more popular.
Individual value is increasingly recognized by the whole society, and plays a vital role in the balance of organization efficiency and innovation [2]. But the formal, rigorous, highly structured bureaucratic organization, still regards the individuals as tool driven by economic interests for achieving organizational profits. Obviously, it does not meet the individuals' demand for value creation in the current era. Second, it is unable to stimulate individual proactive innovation behavior. Many enterprises found that even if they invested substantial contribution, the expected all-involved innovation boom still did not appear. Because bureaucratic organization not only reduces the sensitivity to market changes, but also inhibits the initiative and creativity of individuals. Especially under the compulsion of high power distance and heavy performance pressure, employees tend to succumb to the organization, showing passive innovation behavior. However, "spontaneity" is the essential motive force of leveraging social resources and productivity. It is possible to create value only when innovation is spontaneous, voluntary and active.

This paper innovates and reconstructs a more flexible management mode, which is called all-involved management mode on the basis of the ambidextrous organization theory. On the theoretical side, this paper not only enriches the research of management mode, but also makes up the imbalance between leadership theory and employee theory with considering the rise of employee value. On the practical side, finds the root cause of the failure of all-involved innovation. Namely, traditional management mode is no longer applicable because of the inhibition of the members' enthusiasm, initiative and creativity. While, the all-involved management mode offers the reference value for enterprises to give full play to each individual potential and creativity. This paper uses the case study of Haier to expound the practice way of this mode.

\section{THEORETICAL BASIS}

The traditional resource-based theory and enterprise ability theory are both in the view of premise that the organizations are in a stable external environment. However, with the isolated unilateral markets turning into Internet connected multilateral and global markets, the external environment is getting more and more complicated and turbulent. And uncertainty is increasing substantially. In order to avoid the risk of uncertainty, the organizations need to reduce their reliance on external environment [3]. Therefore, they must further 
excavate and develop internal resources and enhance their own capabilities. The ambidextrous organization theory holds that a successful organization usually has the two capabilities, the socalled ambidexterity, to effectively operate existing resources and to brilliantly adapt to future changes [4]. One is exploitation capacity. Namely, use existing knowledge and skills to optimize the performance of products and services and to improve the efficiency of resource utilizing. Another is exploration ability. That is engaged in the search, adventure, discovery, testing and other innovative activities to bring insight into market technological change and to explore new market opportunities [5]. So, how to balance and promote organizational ambidexterity becomes a difficult problem for enterprises. As the most direct and intimate level that contact with the organization's business and external market environment, employees are undoubtedly the best practitioner and the key driver of organizational ambidexterity. Gibson and Julian proposed the establishment of organizational ambidexterity from an individual level. They believed that organizations should give employees the discretion to allow them allocate time and energy into the "exploitation activity" and "exploration activity" by themselves [6]. A real headache of organization is transformed into how to build a management model to fully develop the spontaneity, initiative and creativity of employees in this fashion.

\section{THE ALL-INVOLVED MANAGEMENT MODE}

\section{A. Definition}

In a stable environment, the organization is considered as an institutionalized management system, characterized by strict hierarchical relations, clear job responsibilities and specific division of tasks. But in a turbulent environment, organizations tend to be organic systems, and rely more on transverse selfcoordination mechanisms [2]. Employees are increasingly exhibiting a high degree of autonomy, coordination, and voluntary maintenance of orderly operation of management activities. In order to give full play to the role of employee strength in promoting organizational ambidexterity, organizations need to build a management mode that enables employees to truly gain "ownership" experience. It is called all-involved management. This paper argues that the allinvolved management provided with openness, freedom and equality, means in the decentralized organizational structure, the leadership and employees constitute multiple management subjects, based on shared values to jointly implement internal and external management activities. It can be understood as the optimal combination of a new organizational form, a new leadership style and new employee characters, which is committed to achieve the common value of the whole organization. This paper will describes the framework of the mode from the perspective of organization, leadership and staff these three levels.

\section{B. Framework}

\section{1) Organizational level}

a) Platform Organization. The all-involved management mode is based on the platform organization structure. The organizational boundaries inevitably become more blurred along with the further open, diversification and networking of the organization. And the organizational structure is developing toward a new trend of platform. The platform has three important features: First, concludes large number of smallscale independent front-ends, which are generally composed of the cross functional employees. Second, advocates bottom-up entrepreneurship, which means that employees can take the initiative to start the creative projects and products. Third, the allocation of resources depends on the internal free market mechanism. Thus it can be seen, the core of platform organization is empowerment, which can stimulate the initiative and creativity of employees to the maximum extent. Employees do not have to follow the regular steps, but through self-driven to seek the best development. Each employee can be understood as his own operator of personal ability.

b) Flexible management. The all-involved management mode advocates flexible management method. Flexible management takes employees as the core of value, avoids the restriction of tough system, relies on the psychological process of employees, and stimulates the initiative and potential of employees from the internal motivation. First, organizations need to create a flexible work environment, and provide an open communication atmosphere to give employees a crossfunctional communication space. Thus, organizations can make full use of informal networks to promote knowledge sharing. Second, the flexible work system is adopted to allow employees to decide their working place, time and manner independently on the premise of guaranteeing the completion of their tasks. In addition, a flexible incentive system is a good choice to stimulate employees' enthusiasm. With the prominent social attributes of employees, organizations cannot maintain their loyalty only through material incentives, but should also pay attention to emotional motivation and career development incentives.

c) Goal community. In this new management mode, the relationship between the organization and employees is an alliance. Hoffman pointed out that organizations and individuals in Internet era should invest in each other to form a strong alliance, together with sustained innovation and a rich treasure trove of wisdom [7]. That is, organizations and employees form a goal community, build full trust, and maintain close cooperation. On the one hand, the organization must understand the capabilities and needs of its employees. From a strategic perspective, train employees in a phased and targeted manner with knowledge and skills. On the other hand, employees must respond to the organization, and actively participate in the activities. Through ways of questioning and suggesting, develop practical and challenging target system together with the organization. It is only the integration of employees and organizations can stimulate everyone's willingness to get involved in goals.

\section{2) Leadership level}

a) Super-leadership. The all-involved management mode is based on super-leadership. Super-leadership is who lead subordinates to achieve self-leadership. It is believed that employees should be regarded as "real leaders" with initiative 
and high sense of responsibility, so as to give full play to improve organizational capabilities [8]. Relying on empowerment, super-leadership can encourage and support employees to influence and transform the surroundings actively. Empowerment is a dual concept: Not only emphasizes "Delegate", but also stresses "Enable". It involves both the actions such as the release of power, the provision of guidance, and the promotion of employee' participation in decisionmaking, as well as the process of enhancing employees' initiative and intrinsic motivation through these actions. In fact, the leader is no longer an absolute power holder or a mere dictator, but a strong supporter of value creation by many independent individuals.

b) Decentralization of power. The all-involved management mode transforms the unitary subject into multiple subject to make management decisions follow the volition of most people. According to traditional thinking, the management subject tends to be who master the capital and power. A serious malady here is that personal orientation and preference may lead to the management process mixed up with personal emotion. The diversification of management subjects means that the core value of organization has transferred from leadership to employees. In fact, the Internet has changed the dynamic relationship between the upper class and the grassroots in the power and authority: Organizational power has spread. The power of leadership is waning. While, the power of employees is increasing. At present, knowledge has become a kind of discourse power. Whoever holds the knowledge has the right to make an impact, and becomes the core of the organization. Discourse power no longer extends from top to bottom, but flows through individuals in the form of networks, producing creativity and creativity.

c) Vision community. In the all-involved management mode, Leadership and employees form a collaborative relationship. With the increase of knowledge work, it is becoming more and more difficult for leaders to cope with every aspect of management. Beyond traditional subordinate relations, leaders and employees establish interdependent relations of cooperation and form a vision community. Under the new relationship, the power of the two tends to be equal, which is consistent with the logical starting point of management. Finding the correct logical starting point of management can support the implementation of management methods and actions to follow a certain logical relationship, so as to achieve the desired management results [9]. Leadership and employees are the two basic concepts of management, but also the basic theoretical framework of solving management issues Balance must be maintained between the two.

\section{3) Employee level}

a) Proactive employees. The all-involved management mode is based on the proactive employees. Zero distance communication inevitably generates a large amount of data, which actually implies the great changes in human needs, personality characteristics, information and knowledge. Specifically speaking: First, the needs of employees tend to diversify. Second, employees can exert their influence and discourse power by means of various media. And the oversight power from the bottom to up is enhanced. Third, they awake their self-consciousness and improve their ability. Especially for the new generation of employees, they always have a strong ability to accept and learn the new knowledge. Based on these changes, they are more and more proactive. That is, actively search opportunities and information, and actively impact and transformation of the environment rather than passively waiting to be managed [10]. Proactive employees are able to take initiative behavior and promote their own innovations. They are more willing to take the time and effort to solve a series of problems encountered in the process of innovation.

b) Self-leadership. In all-involved management mode, employees must become self-leadership. As empowerment increases, employees gradually replace part of the leaders' capabilities and eventually become self-leadership. The internal origin view holds that self-leadership is the process of selfinfluence, which is driven by the individual's needs, based on the intrinsic standards and the necessary self-guidance [11]. The acquisition view holds that self-leadership can be acquired through learning, which has a great potential for development and plays a positive role in the efficiency of individual activities. Combining the two perspectives, this paper argues that employees can be a continuum from external control to internal control. Through self-regulation, self-motivation and self-study, self-leadership can be realized and initiative potentials can be explored and developed. First, employees should establish their own reward and punishment mechanism to adjust behavior. Second, employees should be selfmotivated. Increase self-efficacy and self-control and uses the psychological drive to encourage themselves struggle for the goal. Finally, employees should culture autonomous learning. Enhance their creativity by acquiring knowledge according to their own learning habits and learning methods.

c) Interest community. In all-involved management mode, employees build friendships in teams. At the past times, in the case of hierarchy and segregation, opportunities for employees to contact other departments were limited and relationships mostly confined to formal work. The Internet has broken the barriers of communication within the organization, opened up channels of knowledge sharing, and strengthened cross-department communication among employees. They established closer friendship on the basis of formal working relationships, namely workplace friendship. Workplace friendship provides emotional support, internal rewards, and more information transfer and feedback. It also helps to form a good team climate, raise trust and identity among team members, reduce relationship conflict, increase task conflict, and improve team performance, [12]. In addition, it will increase the willingness to share knowledge and enhance team creativity [13]. In the face of dynamic changing environment, organizations urgently need teamwork to play the " $1+1>2$ " effect. Therefore, the traditional model of division of labor and division of interests has gradually been replaced by team cooperation and new mode of benefit sharing. Employees are no longer fixed in a position. There is no definite project or 
task. Instead, they can build a team and form an interest community with their own capabilities.

\section{APPLICATION: A CASE STUDY OF HAIER}

Haier Group, which was founded in1984, is now one of the world's leading domestic appliance manufacturers. In the Internet era, Haier announced: "We will let everyone become his own CEO". Under the guidance of Internet strategy, Haier completely broke the bureaucracy mode, which was popular for hundreds of years, to build an "Integrating Order with Personnel" mode. That means the users and employees connect together through the organization platform to realize shared value. Namely, employees can achieve self-value and organizational value in the process of creating value for users. There is no doubt that Haier is the pioneer and leader of the allinvolved management mode, which provides valuable experience for enterprises both in China and around the world.

\section{A. Non-boundary organization}

The arrival of the Internet era is both a challenge and an opportunity for the enterprises. Haier CEO Ruimin Zhang takes the lead in putting forward the idea of " non-boundary organization". Haier makes efforts from the following two aspects.

First, rebuilds organizational structure. Haier Collapses the traditional bureaucratic structure of the positive triangle and builds an open, interactive, value sharing platform ecosystem. A reticular structure is built in the platform ecosystem, which breaks the original organization boundaries, attracts and drives internal and external human resources to work together, and encourage members to share and manage their knowledge, further, to create value. Thus, the role of organizations changes from the product service provider to the value creation service provider. Accordingly, the role of employees changes from passive executors of fixed tasks to proactive internal partners. Such changes allow organizations and employees to form a dynamic and symbiotic alliance instead of the original rigid employment relation, realize the integration of organization goals and employee goals, and greatly improve the enthusiasm and initiative of employees.

Second, miniaturizes organization. Haier's miniaturization is adopting flexible management method to break away from the unified control by setting up a large number of selforganizations with business or project as the center. These selforganizations named "micro system" are essentially self-driven enterprises existing on the platform ecosystem. Every micro system is an economic entity with independent operation, independent accounting and full responsibility for profits or losses. And everyone in Haier can join and even found a micro system. If Haier in accordance with the traditional thinking of top-down control to manage more than 2000 micro system, it is impossible to ensure high degree autonomy, rapid-reaction capability, and efficient collaboration simultaneously. So, Haier headquarters decentralizes decision-making power, employment power and distribution power to micro system, aiming to encourage them to produce an amplified effect of energy by mechanism of self-control and transverse collaboration, thus solving the problem of inefficient resource utilization and lack of innovation vitality in large-scale enterprises. As a result, enhance the organizational ambidexterity.

\section{B. Management without leadership}

Haier breaks the traditional power hierarchy and command relationship, and advocates the management of "no leadership", so as to realize the multiple management subjects. Doing so involves all employees in the organization's management and innovation activities. Instead of conducting all aspects of management, leadership is more empowering and changes from resource owners to resource supporters, encouraging employees' self-leadership and open innovation. Thus, the traditional supervisor-subordinate relationship turns into the cooperative relationship between investors and entrepreneurs. In Haier, everyone has equal rights. And two innovative mechanisms are the best proof of this point.

One is called "mutual election mechanism of generals and soldiers". Haier sets up a drive mechanism for interaction between the top and bottom. The leader of micro system is not appointed by superiors, but is screened and optimized by all members in this micro system. Anyone can come up with an implementation plan for the task to apply for leadership through open competition. When a leader is elected, he can form a team of his own. If the management does not achieve the desired goal, internal members can initiate the mutual election proceedings to impeach and reselect the new leader. Such mechanism is essentially a self -regulation mechanism of checks and balances between micro system members, to ensure the team goals and overall interests.

Another is called "Catfish mechanism". In a micro system, leader or key employees must cultivate at least one "catfish" as a replacement. Only after the assessment of "catfish" is qualified can the cultivator be promoted to a higher post. The existence of "catfish", on the one hand, encourages members to remain active because of fierce competition. On the other hand, encourages members to cultivate potential substitutes and maintain a high degree of cooperation with each other. All the members in the micro system must constantly improve their own abilities to ensure sustained innovation and team competition. Catfish mechanism is essentially a mechanism of self-motivation and self-learning. And it is also a concrete practice for Haier to value the development of employees' career.

\section{Every employee is a creator}

Haier has transformed the traditional directive innovation into self-created, self-initiated and self-organized innovation. In Haier, everyone is a creator. Employees can directly face the market terminal demand, offer innovative projects of good market prospects, make full use of the "forced" mechanism to require the enterprise system to provide support resources, and actively drive product innovation and business profitability. In addition, under the driving of market opportunities, they are able to organize a team freely, and start the mutual election mechanism to determine the fate of members. In a certain sense, they become their own CEO, and take responsibility for their own actions and decisions. 
In Haier's platform ecosystem, employees are more likely to produce persistent disruptive innovation, because they are able to interact with users and resources across the globe at zero distance. What's more, depending on the "Integrating Order with Personnel" mode, employees and users can contact with each other in real-time, and participate in the whole process of design, $R \& D$ and manufacture. For example, based on the HOPE (Haier Open Partnership Ecosystem platform), Haier's internal R \& D team integrated 128 experts and scholars from 8 countries to design an intelligent air product, which can be satisfied with the various demands of users. They worked together, and shared views with more than 9,800,000 users worldwide via the Internet. Then, using big data analytics selected 122 product pain points that 810,000 fans most concerned about as a basis for the functional design of the air magic cube. On the list of 2016 retail sales of large household appliances issued by Euromonitor, Haier broke through the fierce competition and won 8 consecutive championships. Up to now, Haier has won 105 world-renowned design awards including IF, Red dot, IDEA, G-mark and so on.

In the process of exploration and practice of management mode, Haier continuously improves its organizational ambidexterity. It not only makes use of existing advantages in the mature market to ensure high efficiency, but also absorbs the global innovation resources in the emerging market to realize the disruptive innovation.

\section{SUMMARY}

In the Internet era, innovation has become an important guarantee for enterprises not only to meet the current competition needs, but also to adapt to the future changes. Chinese enterprises are in a critical period of transition from resource driven to innovation driven. It is still easy for them to fall into the trap of classical contradictory proposition such as the choice of centralization and decentralization and the balance of efficiency and innovation. So, as an open system, organization must have dynamic and strong ambidexterity. This paper argues that establishing ambidexterity from the perspective of individuals can fully stimulate the internal force of the organization to create shared value, which is consistent with Gibson' s view. Based on this point, this paper puts forward the all-involved management mode to help enterprises achieve sustainable innovation and long-term development. Nevertheless, there are still some limitations: Firstly, with innovation becoming a national strategy, China has a special innovation environment that is different from western countries. But the applicability of the mode in China unique context is not discussed. Secondly, the applicability of the mode in different industries, different enterprise types, and different enterprise scales is not discussed. Thirdly, there is no empirical test on the role of the model in employee's innovation behavior and innovation performance. The future research can proceed from these three deficiencies.

\section{REFERENCES}

[1] Huateng Ma, Xiaofeng Zhang Du. Internet plus and national strategic move roadmap [M]. Beijing: CITIC Publishing Group, 2015.(In Chinese)

[2] Chunhua Chen. The arrival of sharing era requires a new paradigm of management [J]. Chinese Journal of Management, 2016, (02): 157-164. (In Chinese)

[3] Lidong Wu, Kai Wang, Haixin Huang. A review of research on the uncertainty of organizational external environment $[\mathrm{J}]$. Chinese Journal of Management, 2012, (11): 1712-1717. (In Chinese)

[4] O’Reilly I C, Tushman M L. Organizational Ambidexterity: Past, Present and Future [J]. Academy of Management Perspectives, 2013,27 (4): 324-338.

[5] March J. Exploration and Exploitation in Organizational Learning [J]. Organization Science, 1991,2 (1):71 87.

[6] Cristina B. Gibson, Julian Birkinshaw. The Antecedents, Consequences, And Mediating Role of Organizational Ambidexterity [J]. Academy of Management Journal, 2004, 47(2): 209-226.

[7] Ning Li. Alliance, employee relations in the E Era: Help to read The Alliance [J]. The Human Resource, 2016, (10): 88-90. (In Chinese)

[8] Shankan He. Logical process of transformation of leadership concept and leadership style: Review of Centennial leadership theory [J]. Exploration and Free Views, 2008, (08): 62-66. (In Chinese)

[9] Xuefeng Ding, Heqing Yang. Three logical starting points of management $[\mathrm{J}]$. Journal of Chongqing University of Technology (SOCIAL SCIENCES), 2013, (10): 53-58. (In Chinese)

[10] Jie Zhang, Yun Fan, Xu Zhang. Employee innovation from the perspective of proactive behavior -- proactive personality, feedback seeking and employee innovation performance [J]. Nankai Business Review, 2014, (05): 13-23. (In Chinese)

[11] Manz,C.. Self-Leadership:Toward an expanded theory of self-influence processes in organizations [J]. Academy of Management Review, 1986, 11(3), 585-600.

[12] Sias S and Avdeyeva T. Sex and sex-composition differences and similarities in per workplace friendship development [J]. Communication studies, 2003, 54 (3): 331-340.

[13] Bing Liao, Yongli Bai. An empirical study on the relationship among employee's work friendship, knowledge sharing intention and creativity of research team $[\mathrm{J}]$. Scientific Decision, 2014,10: 39-49. (In Chinese) 